\title{
Care management from the perspective of supervising nurses
}

\author{
A gestão do cuidado sob a ótica de enfermeiros supervisores
}

Maria Antônia Ramos Costa ${ }^{1}$, Verusca Soares de Souzaํㅜ, João Lucas Campos de Oliveira², Elen Ferraz Teston ${ }^{1}$, Laura Misue Matsuda²

Objective: to understand the perceptions of supervising nurses on care management practices and, collectively, build a concept. Methods: qualitative study, conducted with 15 supervising nurses. The Freire's Culture Circle was used as a data collection technique. The meetings were recorded, transcribed and analyzed according to their thematic structures. Results: through the individual concept, care management was considered as a complex responsibility, focused on bureaucratic actions. The collective concept related management with systematization of care that results in a comprehensive and qualified care. Concerning the difficulties in care management, aspects related to the institution were highlighted, such as the lack of standardization of norms and routines, physical structure and human resources. Conclusion: nurses perceive management and care in a fragmented way and the construction of a collective concept has resulted in the concern with the systematization and organization of the material, physical and human resources necessary for care.

Descriptors: Patient Care Management; Hospital Administration; Education, Nursing; Education, Continuing; Nursing.

Objetivo: compreender as percepções de enfermeiros supervisores sobre as práticas de gestão do cuidado e construir coletivamente um conceito. Métodos: estudo qualitativo, realizado com 15 enfermeiros supervisores. Empregou-se o Círculo de Cultura freireano como técnica de coleta de dados. Os encontros foram gravados, transcritos e analisados segundo suas estruturas temáticas. Resultados: através da concepção individual considerou-se a gestão do cuidado como responsabilidade complexa, com foco em ações burocráticas. A concepção coletiva relacionou a gestão com a sistematização da assistência que resulta no cuidado integral e qualificado. Quanto às dificuldades na gestão do cuidado destacaram-se aspectos relacionados à instituição, como a falta de padronização de normas e rotinas, estrutura física e os recursos humanos. Conclusão: os enfermeiros percebem a gestão e o cuidado de maneira fragmentada e a construção do conceito coletivo resultou na preocupação com a sistematização e a organização dos recursos materiais, físicos e humanos necessários ao cuidado.

Descritores: Administração dos Cuidados ao Paciente; Administração Hospitalar; Educação em Enfermagem; Educação Continuada; Enfermagem.

\footnotetext{
${ }^{1}$ Universidade Estadual do Paraná. Paranavaí, PR. Brazil.

${ }^{2}$ Universidade Estadual de Maringá. Maringá, PR. Brazil 


\section{Introduction}

Nurses' work is a complex phenomenon and a challenge, since it requires broad perspectives of performance in addition to direct care to the patient, since only the technical and assistance aspects developed are not enough to achieve comprehensive and quality care. In this way, the managerial competence of nurses is an unquestionable necessity, since aspects related to the management of the most diverse resources, especially the human ones, directly influence the performance of this professional and their team in favor of qualified assistance ${ }^{(1)}$.

Articulating management and assistance in the nurses' work is a paradigm to be overcome, because the separation of these two dimensions of their work still exist $t^{(2)}$. Despite this, it is possible that management, in the context of nursing, can be understood as a technical/professional, as well as personal/inductive instrument, to enable the practice of care itself, culminating in conditions favorable to direct care $^{(3-4)}$.

Fragility in nurses' knowledge about care management results in a disarticulation between managerial and care work ${ }^{(2)}$, which can sometimes be justified by the lack of training of these professionals with regard to administrative strategies for care ${ }^{(5)}$. In this perspective, a permanent educational process should be implemented for the continuous qualification of these workers, which should critically encompass all the dimensions of their work, including the management of the assistance ${ }^{(6)}$.

It should be noted that permanent education is conceived as a managerial competence to be developed in the training of nurses ${ }^{(3)}$. In this way, it can present itself as a changing tool that assists in the qualification of care, by stimulating professionals to develop the necessary skills to meet the population's health demands that have become notoriously more and more complex ${ }^{(7)}$.

Investigating care management in the perspective of supervising/managing nurses is relevant, since it has the potential to elucidate the phenomenon in question in a more critical and systematic way, and, with this, to favor the elaboration of strategies that culminate in the production of quality of care itself.

As a support to reflect on the improvement of care management, a question arises: how do supervising nurses conceive the practice of care management? In order to answer this question, the objective was to understand the perceptions of supervising nurses on the practices of care management, and to construct a concept collectively.

\section{Methods}

This is a qualitative study performed in a public hospital in the South of Brazil. The institution offers medium and high complexity service and has 150 beds. In addition, it has a nursing staff composed by 30 supervising nurses; 140 nursing technicians and 33 nursing assistants.

Fifteen supervising nurses who met the following inclusion criterion participated in the study: having an employment relationship with the institution and having exercised the position of supervisor of the nursing team for at least six months, a period considered necessary for the minimum experience of the managerial practice on hospital care. Those who were on vacation or leave during the period of data collection were excluded.

Data collection took place from May to July 2014 , using a questionnaire with nine items that included the extraction of participants' characterization data (gender, age, training time, supervision time, graduate studies and area). Subsequently, Paulo Freire's Itinerary Research Method was applied through the technique of the Culture Circle ${ }^{(8)}$, with an average duration of 2 hours and 30 minutes, in the meeting room of the hospital under study. The conduction of the Culture Circle occurred in three moments.

The first moment was the thematic investigation/research, consisting in the search of themes arising from the subjects' daily life, that is, from the daily reality of care management. In this research, the 
generating themes care management and practice of care management were discussed through guiding questions, from which the mediator (a PhD Nurse student in nursing and not participant in the investigated work context) encouraged the participants of the Circle to expose their ideas, opinions and concepts.

Subsequently, codification/decoding of the generative themes was carried out, which occurred at the time of contextualization, when the themes were discussed, questioned and analyzed. Participants were encouraged to elaborate a critical view of the situation and the subject discussed. This allowed the perception of an interface between practice of care management and the other points raised and re-(elaborated) individually and collectively by the group of nurses.

The third and final moment of the Culture Circle was Critical Unveiling. In this stage, the action-reflection-action process occurred to overcome the contradictions of the reality lived by nurses, because it is the phase in which participants become aware about the real situation and the possibilities for change. In other words, this was the moment that legitimized the collective construction on care management by the group and the possibilities arising from the research.

The speeches of the participants of the Culture Circle were recorded in audio and later transcribed in full. In the process of analysis of the transcriptions, several readings were made for organizing the corpus, mapping of common themes and systematic reduction, using the methodological theoretical framework $^{(8)}$ that resulted in two thematic axes: "Individual and collective conception of nurses on care management" and "Difficulties in the practice of care management".

Participants had their identity preserved and were identified by the letter the " $\mathrm{N}$ " for "Nurse", followed by an Arabic number defined according to the chronological order of the collection approach.

The study complied with the formal requirements contained in the national and international regulatory standards for research involving human beings.

\section{Results}

Among the participating nurses, $86.7 \%(n=13)$ were female and $53.3 \%(n=8)$ were in the age range of 24 to 30 years. As for the time elapsed since graduation in nursing, $53.3 \%(\mathrm{n}=8)$ were between two and five years. Nine $(60.0 \%)$ nurses had been in supervisory position for less than five years. Still, $80.0 \%$ $(n=12)$ had graduate studies, and the two areas of post-graduation cited were Health Management and Hospital Administration.

From the analysis of the qualitative data two categories emerged, which present nurses' conceptions and the difficulties in the practice of care management, which will be described next.

\section{Individual and collective conception of nurses on care management}

Regarding the understanding about care management, some participants understand it as a complex responsibility, as can be seen in the following extracts: I think the managerial issue is complex because it involves managing staff, managing care, managing assistance, managing the bureaucratic aspect... (N3). I think that care management started there with Florence because she was the first to establish rules of nursing administration ... What happens today is that we nurses would have to perform the management of direct care to the patient, in addition to managing all the work process routines (N1). When we talk about care management, we are talking about attention to the patient, both in terms of the bureaucratic aspect and the technical aspect (N13). ... Care management is to think about the systematization of nursing care, which is that routine; you make a care plan, apply it and then assess whether it is being effective (N5).

After the individual conception of the nurses, the group constructed its collective conception about care management: ...It is based mainly on the systematization of care that enables comprehensive and quality care, in which it is necessary that the nurse is able to manage material, physical and human resources.

\section{Difficulties in the practice of care management}


When questioned about the practice of care management, aspects related to the institution that hinder management emerged: In my opinion, the greatest difficulty is demotivation by the team and inadequate training of the institution's human resources (N3). I think our difficulty lies in the lack of standardization, with highlight to the norms and routines of nursing procedures (N5). I think that increased patient flow and inadequate physical structure are the difficulties of the institution (N10). Difficulties are the lack of human resources and insufficient technological subsidies (N8).

\section{Discussion}

The realization of this research in only one public hospital can be highlighted as one of its limitations. Moreover, even though the awareness of the concept of care management has partly transposed the dichotomous view between care and management and has promoted a guidance for what is conceived as nurse-managed care in that organization, the fact that a concrete strategy to improve this action has not been clearly identified and the difficulties involved can also be seen as a limitation of this study.

In the nurses' individual concepts, care management is seen as an issue divided into static activities such as team management, care/assistance, and properly administrative actions, listed as a "bureaucratic" part of their work. This perception is translated into a fragmented work practice, since the nurse's work, in a proactive perspective, should harmonize the dimensions of taking care/assisting, researching/teaching, and administering/managing in order to excel in the quality of care provided(9-11).

By dissociating conceptions that involve their work, nurses demand greater critical-reflexive awareness about the aspects of their professional performance. This is because, although the technical dimension - linked to care or management - is necessary for the professional development of the nurse, this professional needs to articulate and conceive their actions in a more rational way, including in the political scope of work, otherwise they may tend to reproduce care, management or any other labor activity in a fragmented and uncritical logic.

In this context, some strategies can be used in order to mitigate the dichotomy between management and assistance in the training of nurses, such as the use of case studies addressing the harmonic performance of managers in favor of direct care, research leagues focused on global education, in addition to curricular restructuring ${ }^{(5)}$. In this scenario, permanent education focused on the real needs of work and active and critical participation of those involved can be valuable in overcoming the anachronistic paradigm that clearly segregates nursing management and care.

To that end, aspects related to the creation and implementation of ideal conditions for the development of assistance, from the nursing team's performance, the necessary physical structure, the material resources and the interventions on care must be planned by the professional who holds the position of manager, who, in the context of care, is most often the nurse ${ }^{(12)}$.

The relationship between care management and the systematization of nursing care indicated by some interviewees is a positive result, since this methodological tool is a valuable link between planning and care, as well as it favors organization and evaluation of the productive process - care - in nursing ${ }^{(13-14)}$. However, it is important to emphasize the importance of considering the expanded concept of care management, which, in addition to the actual care, involves nurses' actions related to leadership, organization, planning and evaluation, considered as indirect actions involved in care $^{(6)}$.

Indirect care in this study refers to the so-called administrative and managerial activities, carried out by the nurse, necessary to adjust conditions and resources aiming at achieving the planned and quality care $^{(6,10-12)}$. Direct care refers to the implementation of nursing actions to meet all patient needs, including aspects related to dialogue, relationships, respect and individuality ${ }^{(10)}$. 
The perception that management of care is related only to direct care to the patient, as it appears in the excerpt of N5, corroborates a study, in which the nurse considered that the lack of time is a limitation for care management, for having to perform bureaucratic services $^{(4)}$. This data points to the non-recognition of many professionals about the importance of these services for care management, which ultimately weakens the identity of the nurse's work.

The collective construction of the care management concept took into account individual opinions and knowledge acquired through discussions, which resulted in a conceptualization focused on the interdependence of care and management activities, intermediated by systematized care and management of resources necessary for care. Thus, the conceptualization elaborated by the group of nurses is in line with affirmations that care and management should be understood in a dialectical way ${ }^{(9-10)}$, which confir$\mathrm{ms}$ that care activities are closely related to management/administration activities. Thus, the collective concept contradicts the individual conceptions of care management initially constructed by nurses, which segregate such actions before care.

This concept constructed collectively by the group of participating nurses transposed the denotation of systematization of care as synonymous with the management of nursing care, since professionals had the ability to mention the management of the resources necessary to provide care as an element of importance to their managerial work. In spite of this, the collective conception did not include relational aspects necessary for the management of resources, and especially of people, such as leadership, communication, and permanent education itself, which are at the heart of managerial competencies ${ }^{(3)}$ and are basic to the practice of humanized and also strategic management.

Care management also includes the continuous mobilization of personal and professional skills that are aimed at improving the viability of the work environment for care $^{(3)}$. Having said that, it is worth reflec- ting that the collective concept of participating nurses tended to the care management directed to technical and instrumental management skills, and little reflected in the interpersonal development in work, which can be a factor that makes it difficult to overcome the barriers experienced, as explained in the participants' speeches.

With regard to the difficulties in the practice of care management, those related to the hospital institution, such as the lack of motivation and qualification of the team, which can also be related to the lack of standardization of the service, were highlighted, as cited by N5. In view of these difficulties, the nursing team must develop in the technical dimension so that professional activities are effective and of quality ${ }^{(11)}$. In order to do so, it is necessary to invest, through lifelong education, in the development of competences aimed at care management, such as the provision of negotiation spaces between team members and the continuous development of communication skills and information management.

These difficulties require both organizational and individual investments in permanent education with the aim of increasing professional qualification based on meaningful learning, in which learning is understood as "learning to learn". To that end, teaching-learning strategies must target at the discussion of situations experienced in the daily work between the involved subjects, which can result in encouragement and motivation for the team, since they all participate in the whole process of thinking about care ${ }^{(4,8-9)}$. Therefore, in addition to contributing to the organization of the work process, permanent education provides personal and professional growth, since it develops from daily problems identified in the service reality ${ }^{(15)}$.

Regarding the difficulty related to the lack of standardization of norms and routines, it is emphasized that the standardization of procedures/behaviors tends to homogenize the work process and this leads to the development of actions that avoid or minimize errors or failures in the care process, favoring managerial actions ${ }^{(10-13)}$. However, the standardization of care 
processes should not be understood as a complication of the care process, but rather as a strategy to promote professional autonomy, in a way that it provides more safety in the performance of procedures, which consequently improves the quality of care provided ${ }^{(4,9)}$. Although there are institutional standardizations, all skills stimulated and developed are provisional and must be constantly evaluated and reconstructed in order to follow the constant changes that accompany the evolution of health services ${ }^{(15)}$.

Once again, a permanent educational process stands as an important individual and institutional strategy to minimize the difficulty related to standardization, since the educational process based on the precepts of Permanent Health Education aims at learning at work, using dialogical methodologies. Thus, the team participating in the process of thinking about care can find, through permanent education, solutions to minimize and solve issues that interfere with care $^{(8,10)}$.

Participants also highlighted difficulties related to the physical structure of that institution, the need for a greater staff of health professionals and improvement in technological subsidies to meet the high flow of users in the hospital service. Therefore, in some situations, problem solving depends not only on qualification, but on other factors that are influenced by the lack of financial and/or human resources ${ }^{(13)}$.

In the participants' perception, difficulties related to the nurse and the institution are associated with the fact that the hospital does not yet have effective actions implemented to improve care management. It is important to note that some of the difficulties listed could be solved through educational actions based on the care process, which reaffirms the importance of the nurse as a care manager, with permanent education as managerial competence in their work. In this sense, nurses could better handle the whole situation that interferes with the care to be managed, and thus, facilitate the decision-making process for improvements, in addition to negotiating with middle and high hospital managers to demand better working conditions.

Despite the limitations, it is believed that this study contributes greatly to the practice of nursing care administration, since it provides support for better articulation between the dimensions of the nurse's work, evidencing that the "administrative" work of this professional certainly should not be separated from the core of their profession, which is care. In addition, the use of instruments and means for this practice must be accompanied by the development of managerial skills.

\section{Conclusion}

Nurses' perception of care management is fragmented. The collective construction on this theme concentrated in the systematized care and management of material, physical and human resources necessary for providing care, which points to the need for permanent education processes for the nursing service.

\section{Collaborations}

Costa MAR and Matsuda LM contributed to the research project design, data analysis and interpretation, article writing, critical review of intellectual content and final approval of the version to be published. Souza VS, Oliveira JLC and Teston EF contributed to the article writing, critical review of the intellectual content and final approval of the version to be published.

\section{References}

1. Silva LAA, Backes VMS, Prado ML. La educación en el trabajo de enfermería en el context latinoamercano. Enferm Global. 2014; 13(34):346-58. doi: http://dx.doi.org/10.6018/ eglobal.13.2.165401 
2. Santos I, Erdmann AL, Santos JLG, Klock P, Martins VV, Brandão ES. The education of healthcare management: a view from the graduates - theory based on data. Online Braz J Nurs [Internet]. 2012 [cited 2016 Fev 10]; 11(3):621-37. Available from: http://www.objnursing.uff.br/index.php/ nursing/article/view/3924/html_1

3. Rosin J, Tres DP, Santos RP, Peres RR, Oliveira JLC. Desenvolvimento de competências gerenciais na enfermagem: experiência entre residentes. Rev Eletr Gestão Saúde [Internet]. 2016 [citado 2017 jun 13]; 7(1):231-46. Disponível em: http:// dx.doi.org/10.18673/gs.v7i1.22077

4. Christovam BP, Porto IS, Oliveira DC. Nursing care management in hospital settings: the building of a construct. Rev Esc Enferm USP. 2012; 46(3):734-41. http://dx.doi.org/10.1590/S008062342012000300028

5. Santos PR, Silva SV, Rigo DFH, Oliveira JLC, Tonini NS, Nicola AL. Management teaching and its implications to nurses formation: a professors perspectives. Cienc Cuid Saúde. 2017; 16(1):e33381. doi: http://dx.doi.org/10.4025/ cienccuidsaude.v16i1.33381

6. Maziero VG, Bernardes A, Spiri WC, Gabriel CS. Building meanings about management assistance: a phenomenological study. Cienc Cuid Saúde [Internet]. 2014 [cited 2016 nov 10]; 13(3):563-70. Available from: http://hdl.handle. net/11449/136919

7. Draper J, Clark L, Rogers J. Managers' role in maximising investment in continuing professional education. Nurs Management. 2016; 22(9):30-6. doi: http://dx.doi.org/10.7748/nm.22.9.30.s29

8. Freire P. Pedagogia do Oprimido. Rio de Janeiro: Paz e Terra; 2013.
9. Bogaert PV, Kowalski C, Weeks SM, Heusden DV, Clarke SP. The relationship between nurse practice environment nurse work characteristics, burnout and job outcome and quality of nursing care: a cross-sectional survey. Int J Nurs Stud. 2013; 50:1667-77. doi: http://dx.doi.org/10.1016/j. ijnurstu.2013.05.010

10. Lucca TRS, Vannuchi MTO, Garanhani ML, Carvalho BG, Pissinati PSC. The meaning of care management attributed by nursing faculty members from the viewpoint of complex thinking. Rev Gaúcha Enferm. 2016; 37(3):e61097. doi: http://dx.doi. org/10.1590/1983-1447.2016.03.61097

11. Versa GLGS, Murassaki ACY, Inoue KC, Melo WA, Faller JW, Matsuda LM. Occupational stress: evaluation of intensive care nurses who work at nighttime. Rev Gaúcha Enferm. 2012; 33(2):7885. doi: http://dx.doi.org/10.1590/S198314472012000200012

12. Santos JLG, Pestana AL, Guerrero P, Meirelles BSH, Erdmann. Nurses' practices in the nursing and health care management: integrative review. Rev Bras Enferm. 2013; 66(2):257-63. doi: http://dx. doi.org/10.1590/S0034-71672013000200016

13. Soares MI, Resck ZMR, Terra FS, Camelo SHH. Systematization of nursing care: challenges and features to nurses in the care management. Esc Anna Nery. 2015; 19(1):47-53. doi: http://dx.doi. org/10.5935/1414-8145.20150007

14. Penedo RM, Spiri WC. Meaning of the Systematization of nursing care for nurse managers. Acta Paul Enferm. 2014; 27(1):86-92. doi: http://dx.doi. org/10.1590/1982-0194201400016

15. Salum NC, Prado ML. The permanent education in the development of nursing professionals competences. Texto Contexto Enferm. 2014;23(2):3018.doi:http://dx.doi.org/10.1590/010407072014002160001 